\title{
Clinical Presentation of Joint Hypermobility Syndrome of the Knee in Jordanian Military Personnel
}

\section{Moh'd Rami AlAhmar*, Kreem Al Rashdan, Deifallah Al Sharari, Awni Al Hdead, Zaid Al Dhamsheh and Ibrahim Amayreh}

Physical Medicine and Rehabilitation Department, Amman, Jordan

*Corresponding Author: Moh'd Rami AlAhmar, Physical Medicine and

Rehabilitation Department, Amman, Jordan.
Received: July 30, 2020

Published: August 08, 2020

(C) All rights are reserved by Moh'd Rami

AlAhmar., et al.

\begin{abstract}
Objective: To describe the findings of clinical presentation, complication, radiographic and laboratory of the knee among Jordanian military personnel diagnosed to have hyper mobile syndrome.

Methods: A prospective cohort descriptive study carried out at Royal Rehab Centre in King Hussein Medical Centre, over a period of 2 year (from May 2016 to May 2018). One hundred and twenty military patients complaining of knee problem who attended the rehabilitation clinic and diagnosed with hypermobility were enrolled in this study. Their age, sex, presenting features, clinical profile, laboratory and radiological parameters were studied.

Results: (102 males, and 18 females with M: F ratio 5.7:1), their mean age was 25.6 (range: 17-35 years), mean duration of symptoms 10.3 months.

The most common presenting complain was bilateral knee pain (72 patients, $60 \%)$ followed by unilateral knee pain (35 patients, 29\%), while pain and swelling were noted in 10 patients (8\%) and joint locking was observed in 3 patients (2.5\%).

The commonest radiographic abnormality was premature osteoarthritis seen in 30 patients (25\%) followed by ligament injury observed in 5 patients (4\%), while bone bruising and contusion were documented in 3 patients (2.5\%), stress fracture was reported in 2 patients (1.7\%). Rheumatoid factor and anti-nuclear antibody were found to be positive in 7 patients (5.8\%) and 5 patients (4\%) respectively.

Conclusion: While most people with hypermobile joints remain asymptomatic a small number may have a wide range of musculoskeletal symptoms.

Hypermobility of the knee can predispose early osteoarthritis in this age group of military personnel moreover due to repetitive stress and prolonged standing in static posture, ligament or tendon injury, bone contusion and stress fracture may occur.

Keywords: Benign Hypermobility Syndrome; Knee Hypermobility; Marfan's Syndrome; Ehler Danlos Syndrome; Beighton Score; Brighton Criteria
\end{abstract}

\section{Introduction}

Hypermobility syndrome is often under-recognized and It's just simply means that one can move some or all his $\backslash$ her joints more than most people can, it is known also as Benign Joint Hypermobility Syndrome (BJHS) when symptoms of systemic rheumatologic disease is absent [1].
Hypermobility may occur in several different diseases of the connective tissue including Marfan Syndrome, Ehler Danlos syndrome (EDS), and osteogenesis Imperfecta [2].

It can also be found in chromosomal and genetic disorders like Down Syndrome and metabolic disorders like homocystinuria and hyperlysinemia [3]. 
Although Joint laxity can be harmful as it is associated with recurrent dislocation of the shoulder and patella as well as other orthopedic abnormalities, high level of flexibility can be an advantage for some people, particularly dancers and athletes.

Suspected subject with hypermobility is diagnosed by Brighton Criteria and assessed by Beighton score which is a modification of the original score reported by Beighton., et al. [4,5] and expansion of the original work of Carter and Wilkinson [6]. Patients were given a numerical score of 0 to 9 , one point being allocated for the ability to perform each of the following tests (Table 1 and figure A-E), one point is gained for each side of the body for the first four maneuvers listed below, such that the hypermobility score is a maximum of 9 if all are positive.

Passive dorsiflexion of the fifth metacarpophalangeal joint to $\geq 90^{\circ}$ ( 1 point for left; 1 point for right) (Figure A)

Opposition of the thumb to the volar aspect of the ipsilateral forearm (1 point for left; 1 point for right) (Figure B1,2)

Hyperextension of the elbow to $\geq 10^{\circ}$ ( 1 point for left; 1 point for right) (Figure C)

Hyperextension of the knee to $\geq 10^{\circ}$ ( 1 point for left; 1 point for right) (Figure D)

Placing of hands flat on the floor without bending the knees (1 point) (Figure E)

Table 1: Beighton score [8].
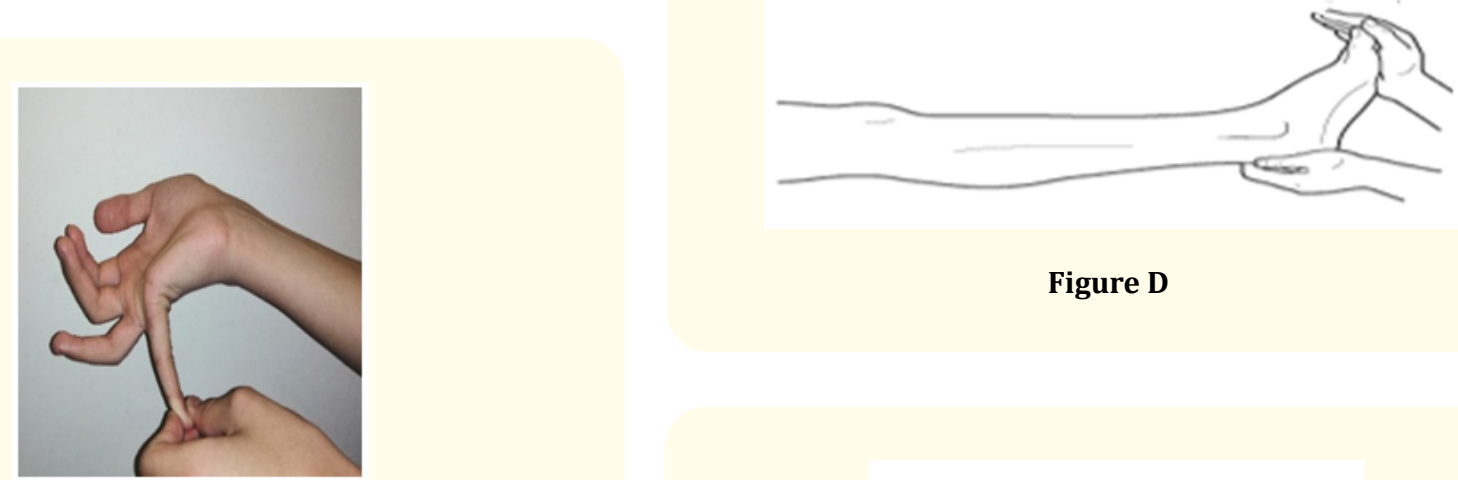

Figure D

Figure A
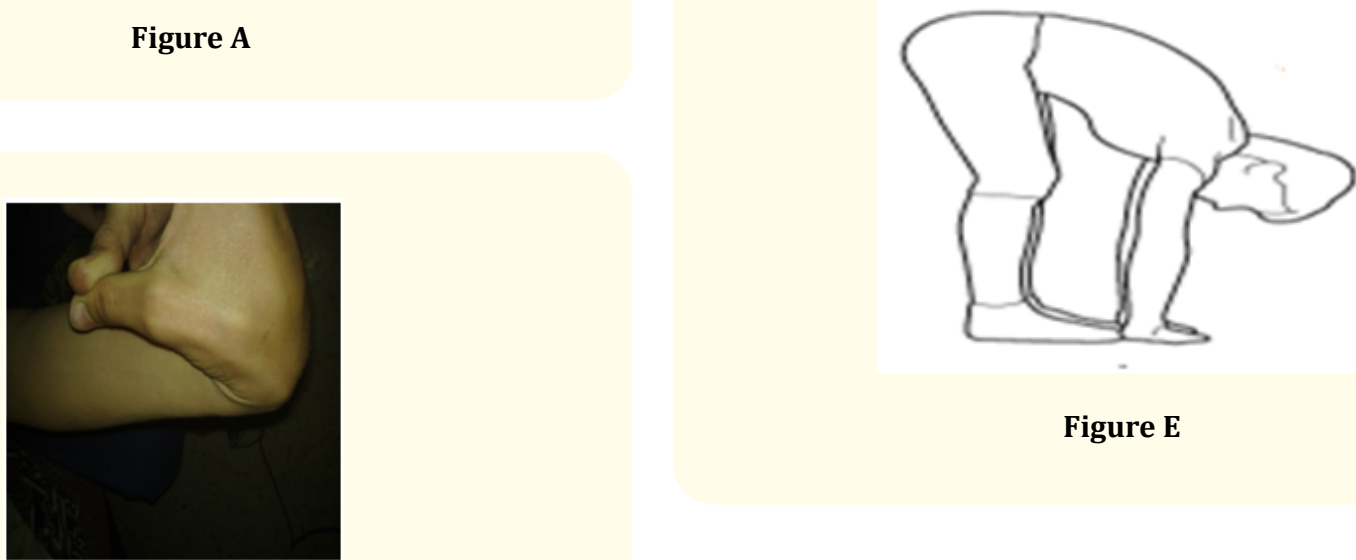

Figure E

Figure B1 
The purpose of this study was to evaluate the prevalence of joint hypermobility amongst Jordanian military personnel who attended the PM\&R clinic at RRC-KHMC and to describe the clinical presentation of their knee problems.

The diagnosis of joint hypermobility syndrome involves two major criteria, one major criterion plus two minor criteria or four minor criteria [7] (Table 2).

\section{Major criteria}

A Beighton score of $4 / 9$ or greater (either currently or historically)

Arthralgia for longer than 3 months in four or more joints

Minor criteria

A Beighton score of 1,2 or $3 / 9(0,1,2$ or 3 if aged $50+)$

Arthralgia ( $>3$ months), in one to three joints or back pain ( $>3$ months), spondylosis, spondylolysis/spondyloslisthesis.

Dislocation/subluxation in more than one joint, or in one joint on more than one occasion.

Soft tissue rheumatism, at least three lesions (e.g. epicondylitis, tenosynovitis, bursitis).

Marfanoid habitus (tall, slim, span/height ratio $>1.03$, upper: lower segment ratio less than 0.89 , arachnodactily (positive Steinberg/wrist signs).

Abnormal skin: Striae, hyperextensibility, thin skin, papyraceous scarring.

Eye signs: Drooping eyelids or myopia or antimongoloid slant.

Varicose veins or hernia or uterine/rectal prolapse.

Table 2: The Brighton revised diagnostic criteria for Benign Joint Hypermobility Syndrome (BJHS) [8].

\section{Methods}

A prospective cohort descriptive study carried out at Physical Medicine and Rehabilitation (PM\&R) clinic, Royal Rehab Centre (RRC), King Hussein Medical Centre (KHMC), over a period of 2 year (from May 2016 to May 2018). Only military patients fulfilled the Brighton revised diagnostic criteria of (BJHS) and have a Beighton score of 4 or more including the knees were enrolled in this study.

A total of 2787 civilian and military patients who had attended the (PM\&R) clinic were investigated only 120 patients fulfilled the inclusion criteria and were included.
Patient's evaluation which include history, physical examination, laboratory and imaging was conducted to exclude rheumatologic and other systemic illness and to confirm the presence of joint hypermobility. Clinical presentations of knee problems were observed and the accumulated data were collected.

The study protocol was approved by the local ethics committee of the Jordanian Royal Medical services.

\section{Statistical analysis}

Statistical Package for Social Sciences version 21.0 (SPSS) was used for analysis of data. Descriptive statistics have been presented as percentages and means with standard deviation (SD). Differences in duration of symptoms and percentages between groups were tested for statistical significance using t-test. The two-tailed probability value $\mathrm{P}<0.005$ was considered statistically significant.

\section{Results}

One hundred and two (102) males, eighteen (18) females fulfilled the Brighton diagnostic criteria of benign hyper mobility syndrome out of 2787 patients who had attended the (PM\&R) clinic with a prevalence of (4.3\%), male to female ratio 5.7:1, their mean age was (25.6 $\pm 4.3 \mathrm{SD})$ years, and the age ranging between $17-35$ years, while the mode was 22 years. Mean duration of symptoms was $(10.3 \pm 4.2 \mathrm{SD})$ months (Table $3-5)$, its range was 95 months $(5-100)$.

\begin{tabular}{|l|c|c|c|c|}
\hline $\begin{array}{l}\text { Age groups } \\
\text { (Years) }\end{array}$ & Frequency & Percent & $\begin{array}{c}\text { Valid } \\
\text { Percent }\end{array}$ & $\begin{array}{c}\text { Cumulative } \\
\text { Percent }\end{array}$ \\
\hline $17-20$ & 6 & 5.0 & 5.0 & 5.0 \\
\hline $21-24$ & 50 & 41.7 & 41.7 & 46.7 \\
\hline $24-29$ & 40 & 33.3 & 33.3 & 80.0 \\
\hline $30-34$ & 20 & 16.7 & 16.7 & 96.7 \\
\hline 35 & 4 & 3.3 & 3.3 & 100.0 \\
\hline Total & 120 & 100.0 & 100.0 & \\
\hline
\end{tabular}

Table 3: Percentage of joint hypermobility according to age.

\begin{tabular}{|l|c|c|c|}
\hline & N & Mean & Std. Deviation \\
\hline $\begin{array}{l}\text { Duration of symptoms } \\
\text { (Month) }\end{array}$ & 120 & 10.3167 & 4.19079 \\
\hline
\end{tabular}

Table 4: Mean duration of symptoms (month). 


\begin{tabular}{|l|c|c|c|c|c|c|}
\hline \multirow{2}{*}{} & \multicolumn{5}{|c|}{ Test Value = 0 } & \multicolumn{2}{c|}{$\begin{array}{c}\text { 95\% Confidence Interval of } \\
\text { the Difference }\end{array}$} \\
\cline { 2 - 7 } & $\mathbf{t}$ & df & Sig. (2-tailed) & Mean Difference & \multicolumn{2}{c|}{ Upper } \\
\cline { 3 - 7 } & & & & 25.57500 & 24.7749 & 26.3751 \\
\hline $\begin{array}{l}\text { Age } \\
\text { (Month) }\end{array}$ & 63.296 & 119 & .000 & 10.31667 & 9.5591 & 11.0742 \\
\hline
\end{tabular}

Table 5: Relationship between duration of symptoms and age.

In our study the most common presenting complains was bilateral knee pain, it was observed in seventy two (72) patients, (60\%), followed by unilateral knee pain thirty five (35) patients, (29\%), pain and swelling was noted in ten (10) patients, $(8 \%)$ while joint locking was detected in three (3) patients $(2.5 \%)$.

On the other hand the most common radiographic abnormality was premature osteoarthritis which has been seen in thirty 30 patients $(25 \%)$ followed by ligament injury observed in five (5) patients (4\%), bone bruising and contusion were documented in three (3) patients (2.5\%), while stress fracture was reported in two (2) patients (1.7\%) (Table 6, 7 and figure F).

Rheumatoid factor and anti-nuclear antibody were found to be a positive rheumatologic laboratorial markers in seven (7) patients (5.8\%) and five (5) patients (4\%) respectively.

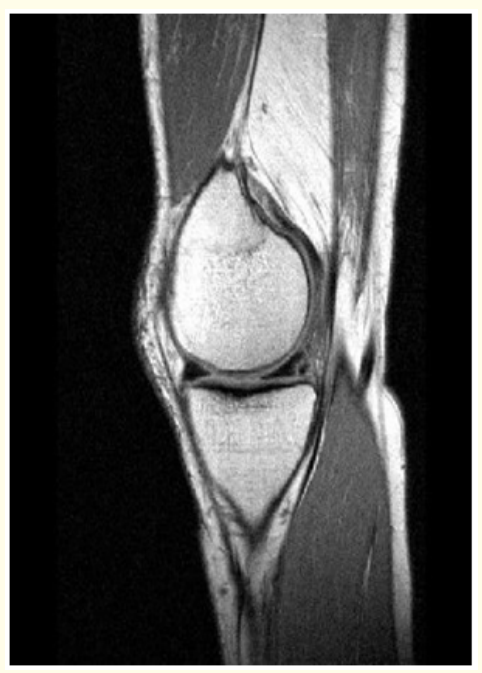

Figure F: T1 weighted MRI of the knee shows tear in the posthorn of med. Meniscus.

\begin{tabular}{|l|c|}
\hline Clinical presentation & Percentage \\
\hline Bilateral knee pain & 72 patients $(60 \%)$ \\
\hline Unilateral knee pain & 35 patients $(29 \%)$ \\
\hline Knee swelling & 10 patients $(8 \%)$ \\
\hline Knee locking & 3 patients $(2.5 \%)$ \\
\hline Back pain & 30 patients $(25 \%)$ \\
\hline Marfanoid features & 15 patients $(12.5 \%)$ \\
\hline
\end{tabular}

Table 6: Percentage of clinical presentations.

\begin{tabular}{|l|c|}
\hline Radio-graphic findings & Percentage \\
\hline premature osteoarthritis (plane x-ray) & 30 Cases $(25 \%)$ \\
\hline ligament injury (MRI) & 5 Cases $(4 \%)$ \\
\hline Bone bruising/contusion (MRI) & 3 Cases $(2.5 \%)$ \\
\hline Stress fracture MRI) & 2 Cases $(1.7 \%)$ \\
\hline
\end{tabular}

Table 7: Percentage of radiographic findings.

\section{Discussion}

Literature was replete with studies confusing BJHS with generalized hypermobility [9]. For this reason, several authors believe JHS is frequently misdiagnosed and more prevalent than is suggested by the current literature. This study has investigated the prevalence of (BJHS) among military Jordanian (4.3\%), using the Beighton score, a similar study by Gautam Mullic., et al. at the department of Rheumatology, Army Hospital Research and Referral, New Delhi, India had shown a lesser comparable prevalence (3.37\%) [1], in contrast to a previous study done by Grahame R., et al. estimated the exact population prevalence upto $30 \%$ of unselected patients presenting with non-inflammatory disease to a general rheumatology outpatient clinic, another study from Kuwait AL-Jarallah K., et al. found that prevalence was (22.3\%) between his sample $[10,11]$ (Table 8). 


\begin{tabular}{|c|c|c|c|c|c|c|}
\hline $\begin{array}{c}\text { Author } \\
\text { (et al.) }\end{array}$ & Population & Study setting & Year & $\begin{array}{c}\text { Sample } \\
\text { size }\end{array}$ & Age group & $\begin{array}{c}\text { Prevalence } \\
\text { of BJHS (\%) }\end{array}$ \\
\hline Kwon & Korea & Work-place & 2013 & 266 & $(24-50)$ & 36.5 \\
\hline Al- Rawi & Iraq & University & 1985 & 1774 & $(20-24)$ & 29.8 \\
\hline Cheng & China & School & 1991 & 2360 & $(3-13)$ & 28.0 \\
\hline Al-aDallah & Kuwait & University & 2014 & 390 & $(18-29)$ & 22.3 \\
\hline Poutain & Oman & Community & 1992 & 920 & $(6-25)$ & 20.4 \\
\hline Kumar & India & Clinics & 2006 & 2050 & $(13-61)$ & 20.0 \\
\hline Seow & Singapore & Community & 1999 & 306 & $(15-39)$ & 17.0 \\
\hline Seckin & Turkey & School & 2005 & 861 & $(13-19)$ & 11.7 \\
\hline nem & New Zealand & Community & 2002 & 804 & $(>5)$ & 6.2 \\
\hline
\end{tabular}

Table 8: Prevalence of joint hypermobility as published for Asian-Pacific regions [11].

We compared our results with available data previously published about BJHS. It suggest a trend towards declining condition prevalence with age mounting [12], which is explained in our study, the mean age was $(25.5 \pm 4.3 \mathrm{SD})$ years, ranging between $17-35$ years. The reduction in joint mobility with age is attributed to increased intrafibrillar cross-links in collagen with advancing age, the collagen in flexor tendons and volar plates getting stiffer in the elderly and also because of progressive biochemical changes in collagen structures that result in stiffening of connective tissue components of joints [10]. The present study also showed a significant relationship between age group and duration of symptoms (P $<0.000$ ) (Table 5 and 8).

There appears to be differences between studies regarding gender, in our study we found highly significant difference between sexes; male to female ratio 5.7:1 $(\mathrm{P}<.001)$. The specialized population of military personnel as the population at risk is a limitations of this study it is less frequently diagnosed, particularly in female soldiers $[13,14]$.

Literature undervalues the prevalence of BJHS since patients with BJHS do not seek medical care, their symptoms are often mild and self-limiting [15]. However, BJHS is associated with multiple medical conditions which can influence function. In our study group a descending pattern of clinical presentations of knee, back, marfanoid features was observed and the most common presenting complains was bilateral knee pain which was observed in (60\%), (72) patients who all had presented with severe exertional knee joint pain, followed by unilateral knee pain (35) patients, (29\%), and joint locking which was detected in (3) patients (2.5\%), these findings are comparable to literatures.

It is well established that patients with hypermobile joints who are routinely exposed to physical activities are prone to develop joint dislocation, traumatic synovitis or early O.A, our findings were an evidence of knee osteoarthritis (O.A) in 30 patients, with synovitis and painful swelling in ten of these patients. However, synovial fluid analysis revealed a non-inflammatory picture [16,17].

Five (5) (4\%) patients sustained ligament injury, bone bruising and contusion were documented in three (3) patients (2.5\%), while stress fracture was reported in two (2) patients (1.7\%), comparable to a similar study among soldiers from Spain which supports the concept that excessive physical activity leads to musculoligamentous lesions in hypermobile patients [18].

Rheumatoid factor and anti-nuclear antibody were found to be a positive rheumatologic laboratorial markers in seven (7) patients $(5.8 \%)$ and five $(5)$ patients $(4 \%)$ respectively.

\section{Conclusion}

While most people with hypermobile joints remain asymptomatic, a small number may have a wide range of musculoskeletal symptoms.

Hypermobility of the knee can predispose early osteoarthritis in this age group of military personnel, moreover due to repetitive stress and prolonged standing in static posture, ligament or tendon injury, bone contusion and stress fracture may occur. 
Physicians are largely unaware of the condition leading to miss diagnosis and patients jump through various specialties without having the precise diagnosis leading to work related suffering, anxiety, depression and increased absenteeism.

\section{Bibliography}

1. Mullick G., et al. "Clinical profile of benign joint hypermobility syndrome from a tertiary care military hospital in India". International Journal of Rheumatic Diseases 16.5 (2013): 590-594.

2. Neki NS and Chhabra A. "Benign joint hypermobility syndrome". Journal of Mahatma Gandhi Institute of Medical Sciences 21.1 (2016): 12.

3. Covaci S., et al. "Benign joint hypermobility syndrome". Romanian Journal of Rheumatology 26.1 (2017).

4. Beighton P., et al. "Ehlers-Danlos syndromes: revised nosology, Villefranche, 1997". American Journal Of Medical Genetics 77.1 (1998): 31-37.

5. Beighton P., et al. "Articular mobility in an African population". Annals of the Rheumatic Diseases 32.5 (1973): 413.

6. Carter C and Wilkinson J. "Persistent joint laxity and congenital dislocation of the hip". The Journal of bone and Joint Surgery 46.1 (1964): 40-45.

7. Larsson L-G., et al. "Benefits and disadvantages of joint hypermobility among musicians". New England Journal of Medicine 329.15 (1993): 1079-82.

8. Ross J and Grahame R. "Joint hypermobility syndrome". BMJ 20 (2011): 342.

9. Grahame R and Hakim AJ. "Hypermobility". Current Opinion in Rheumatology 20.1 (2008): 106-110.

10. Grahame R and Hakim A. "High prevalence of joint hypermobility syndrome in clinic referrals to a north London community hospital". Rheumatology: OXFORD UNIV PRESS GREAT CLARENDON ST, OXFORD OX2 6DP, ENGLAND (2004).

11. Al-Jarallah K., et al. "Prevalence of joint hypermobility in $\mathrm{Ku}-$ wait”. International Journal of Rheumatic Diseases 20.8 (2017): 935-940.

12. Adib N., et al. "Joint hypermobility syndrome in childhood. A not so benign multisystem disorder?" Rheumatology 44.6 (2005): 744-750.
13. Decoster LC., et al. "Prevalence and features of joint hypermobility among adolescent athletes". Archives of Pediatrics and Adolescent Medicine 151.10 (1997): 989-992.

14. Scher DL., et al. "Incidence of joint hypermobility syndrome in a military population: impact of gender and race". Clinical Orthopaedics and Related Research ${ }^{\circledR} 468.7$ (2010): 1790-1795.

15. Kirk J., et al. "The hypermobility syndrome. Musculoskeletal complaints associated with generalized joint hypermobility". Annals of the Rheumatic Diseases 26.5 (1967): 419.

16. Beighton PH., et al. Hypermobility of joints: Springer Science and Business Media (2011).

17. Bird H., et al. "Joint hypermobility leading to osteoarthrosis and chondrocalcinosis". Annals of the Rheumatic Diseases 37.3 (1978): 203-211.

18. Diaz MA., et al. "Joint hyperlaxity and musculoligamentous lesions: study of a population of homogeneous age, sex and physical exertion". Rheumatology 32.2 (1993): 120-122.

\section{Assets from publication with us}

- Prompt Acknowledgement after receiving the article

- Thorough Double blinded peer review

- Rapid Publication

- Issue of Publication Certificate

- High visibility of your Published work

Website: www.actascientific.com/

Submit Article: www.actascientific.com/submission.php Email us: editor@actascientific.com

Contact us: +919182824667 